\title{
Gıda Sanayinde Kullanılan AISI304 ve AISI316 Paslanmaz Çeliklerin Elektro Erozyon ile İşleme (EEI) Performanslarının Araştırılması
}

\author{
Oğuz Erdem * \\ Mühendislik-Mimarlık Fakültesi, Makine Mühendisliği Bölümü, Kırşehir Ahi Evran Üniversitesi, Türkiye
}

\begin{abstract}
Özet
Gıda sanayi; gıdaların üretimi, işlenmesi, muhafazası, ambalajlanması ve nakliyesini konu alan sanayi dalıdır. Sağladığı katma değer ve satış hasılatları açısından değerlendirildiğinde Türkiye'de ve dünyada sosyo-ekonomik bakımdan kritik önem arz etmektedir. Son yıllarda gıda işleme makinelerinde AISI304 ve AISI316 paslanmaz çeliklerin kullanımı oldukça artmaktadır. Bu makinelerin bazı bileşenlerinde kullanılan aşırı sert ve karmaşık geometrili parçaların imalatı için EEİ yönteminin uygunluğunun araştırılması bu çalışma kapsamında incelenmiştir. $\mathrm{Bu}$ amaçla, farklı işleme parametreleri kullanılarak AISI304 ve AISI316 östenitik paslanmaz çelikleri dalma elektro erozyon tezgahında işlenmiştir. Deneysel çalışma sonucunda elde edilen performans çıktıları ve işlenmiş yüzey görüntüleri karşılaştırılmıştır.
\end{abstract}

Anahtar kelimeler: Elektro erozyon ile işleme, Gıda işleme makineleri, Östenitik paslanmaz çelikler

\section{Investigation of Electrical Discharge Machining (EDM) Performances of AISI304 and AISI316 Stainless Steels Used in Food Industry}

\begin{abstract}
Food industry is the industry that deals with the production, processing, preservation, packaging and transportation of foods. When evaluated in terms of the added value and sales revenues it provides, it is of critical importance in point of socio-economic in Turkey and the world. In recent years, the use of AISI304 and AISI316 stainless steels in food processing machines has increased considerably. The investigation of the suitability of the EDM method for manufacturing of extremely hard and complex geometric parts used in some components of these machines has been investigated in this study. For this purpose, AISI304 and AISI316 austenitic stainless steels were machined in a die sinking EDM machine using different machining parameters. Performance outputs obtained from the experimental work and machined surface images were compared.
\end{abstract}

Key words: Electrical discharge machining, Food processing machines, Austenitic stainless steels

*Corresponding author: Address: Mühendislik-Mimarlık Fakültesi, Makine Mühendisliği Bölümü, Ahi Evran Üniversitesi, 40100, Kırşehir TÜRKIYE. E-mail address: oguz.erdem@ahievran.edu.tr, Phone: +903862803825 


\section{Giriş}

Gelişen teknolojiyle paralel olarak üretim endüstrisinde kullanılan malzemelerde çeşitlilik her geçen gün artmakta ve artan bu çeşitlilikle beraber makine parçalarından istenen yüksek sıcaklığa dayanım, yüksek mukavemete ve sertliğe sahip olma ve karmaşık geometri gibi özellikler, bu malzemelerin geleneksel talaşı imalat yöntemleriyle işlenmesini zorlaştırmaktadır [1]. Bu bağlamda, imalat sanayinde Elektro Erozyon ile İşleme (EEI) yöntemi, sert ve işlenmesi zor malzemelerin yanı sıra [2, 3], kompozit malzemelerin [4], süper alaşımların [5], östenitik paslanmaz çeliklerin $[6,7]$ ve 1sıl dirençli çeliklerin işlenmesine olanak sağlayan, önemli bir alışılmamış imalat yöntemidir [8].

EEİ, iletken işparçası ve elektrot arasındaki kıvılcım mekanizmasıyla gerçekleşir. İşleme anında işparçası ve elektrot arasındaki dielektriğin kırılmasıyla bir plazma kanalı oluşur. Plazma kanalı, pozitif iyonlar ve elektronlardan oluşur ve oldukça iletkendir. Bu bölgede iyon yoğunluğu neredeyse elektron yoğunluğuna eşittir ve plazma elektriksel olarak nötrdür. İşparçası ve elektrot arasındaki voltaj farkı bu nötr plazma bölgesinde barındırılmaktadır [9]. Dielektrik sıvı içerisinde bulundurulan işparçası ve elektrot arasında yüksek frekansa sahip kontrollü elektriksel boşalımlar sayesinde işparçası yüzeyinden ergitme ve buharlaştırma yoluyla talaş kaldırılır [10]. EEİ'nin eşsiz elektro-termal ve temassız erozyon özellikleri, geleneksel imalat yöntemlerinde talaş kaldırmak için gerekli olan mekanik kuvvetleri ortadan kaldırmaktadır [11]. Bu sayede işlenecek malzemenin mukavemet ve sertlik değerlerinin hiç bir önemi yoktur [12]. Günümüzde EEİ yöntemi, dalma elektro erozyon [13], tel erozyon [14] ve EEİ delik delme [15] çeşitleriyle imalat sektörüne oldukça büyük katkılar sağlamaktadır. Yöntem, yaygın olarak pres döküm kalıpları, soğuk şekillendirme kalıpları, dövme kalıpları, plastik enjeksiyon kalıpları, toz sıkıştırma kalıpları, kesme ve ezme kalıpları, cıvata başı şişirme kalıpları, çok küçük pompa, motor, robot gibi mikro elektro-mekanik sistemlerin parçaları, nükleer güç reaktörlerinin parçaları, gıda işleme makineleriyle ilgili parçaların üretiminde kullanılmaktadır [10, 16-18].

1900'lü yıllardan itibaren günümüze kadar araştırma konusu olan paslanmaz çeliklerin 170'den fazla türü sanayide; yüksek güvenlik gerektiren nükleer santraller ve güç santralleri, basınçlı kaplar, buhar kazanları, hidrolik kontrol sistemleri, boru ve bağlantı elemanları gibi birçok alanda kullanılmıştır [19]. 20.yy'nin ikinci yarısından itibaren paslanmaz çelikler gıda sanayinde çok geniş kullanım alanları bulmaya başlamıştır. Gıda işleme makineleri, gıda işlemede işgücü verimliliğini artıran, maliyetleri düşüren, modern üretim teknolojilerinin kullanılmasıyla proseslerin zamanında ve insan sağlığına uygun şekilde yapılmasını sağlayarak ürün kalitesi doğrudan artırmaktadırlar. $\mathrm{Bu}$ sebepten, gida makinelerinin tasarımları esnasında doğru malzemelerin seçilmesi büyük önem arz etmektedir. Daha açıklık getirmek gerekirse, birçok gida üretilirken farklı amaçlarla yapılarına katkı maddeleri ilave edilir. Bu maddelerden tuz oldukça fazla miktarda kullanılır. Örneğin salça imalatında tuz kullanımı oldukça fazla olduğundan burada çukurcuk (pitting) korozyonu oluşmaması için yüksek alaşımlı krom nikel paslanmaz çeliklerin kullanımı yaygındır. Benzer şekilde bira ve şarap üretimi sırasında içecekler içerisinde bulunan mikro organizmaların, üretilen içeceğin kalitesine doğrudan etki etmesinden dolayı AISI304 ve AISI316 östenitik paslanmaz çelikleri sahip oldukları hijyen özelliklerinden ötürü bu sektörde kullanılan depolama ve üretim tankları, borular, pompalar ve 1sı değiştiricilerinde kullanılmaktadır. Yine, et işleme tesislerinde AISI316 paslanmaz çelik kancalar hem et suyundan 
oluşan kimyasal korozyona hem de temizlik için kullanılan temizleyici kimyasalların oluşturduğu korozyona karşı daha dayanıklı oldukları için yaygın şekilde kullanılmaktadırlar. Bu örneklere ilaveten, gıda sanayinde kullanılan karıştırıcılarda, fermantasyon tanklarında, borularda, valflerde, distilasyon ünitelerinde, kurutma firınlarında, depolama tanklarında, inkübatörlerde, otoklavlarda, paketleme makineleri ve gıda imalatında kullanılan makinelerin diğer aksam ve parçalarında östenitik paslanmaz çelikler oldukça fazla tercih edilmektedir [20].

Kuru gıdaların işlenmesinde oluşan sürtünmeler yüzeylerde aşınma meydana getirir. Bu durum zamanla sadece yüzey pürüzlülüğünü artırmaz aynı zamanda temizleme problemlerini de beraberinde getirir. Ayrıca sürtünme nedeniyle oluşan yerel sıcaklık farklılıkları mikropların üremesine olanak sağlar. Benzer durum sıvı gıdaların işlenmesinde de geçerlidir. Eğer bir boru içerisinden aşındırıcı partiküller barındıran ve hızla akan bir sıvı gıda geçirilirse, boru iç yüzeyinde oluşan türbülans, basınç dalgaları ve kabarcıklar tahribatlar oluşturarak yüzeyi hasara uğratırlar ve bu istenmeyen bir durumdur. Paslanmaz çeliklerin sert yüzeyleri sayesinde erozyonlar minimum düzeyde gerçekleşir ve gıda artıklarının yüzeye yapışması engellenir. Ayrıca, paslanmaz çelikler için yapılan klinik testler sonucunda paslanmaz çeliklerin gıda ile temas halindeki diğer malzemelerden daha hijyenik oldukları kanıtlanmıştır. Yapılan testlere göre metal olmayan malzemelerin yüzeyinde meydana gelen aşınmalar sonucu yüzeyde yoğun bakteri oluşumu (zehirli oluşumlar) meydana gelmektedir. Fakat paslanmaz çelik yüzeylerde böyle bir oluşum görülmemiştir. Genel olarak yüzey ne kadar pürüzlü ise gıda artıklarının yüzeye yapışması o kadar kolay ve temizlenmesi de o kadar zordur. Özellikle makineyi yerinde temizleme durumunda bu artıkları mekanik yolla temizlemek neredeyse imkansız hale gelmektedir. Gida sanayinde kullanılan levhalar, borular ve makine parçalarında yüzey pürüzlülük değerleri için ortalama yüzey pürüzlülüğü değeri $\left(R_{a}\right)$ tercih edilir. $B u$ değer özellikle içlerini (detaylarını) tam olarak göremediğimiz makine parçaları için çok önemlidir. Çünkü dış (görünür) yüzeylerin pürüzlülüğünü ölçmek ve kontrol etmek kolay şekilde yapılabilirken, iç yüzeyler için bu oldukça güçtür. DIN EN 10088-2'ye göre gida işleme makinelerinin yüzeylerinde $R_{a}$ değeri $0,5 \mu \mathrm{m}$ olması gerekir ama bu değer uzun yıllar $A B$ direktifleri EC98/37/EC Machinery Directive yönergesine göre gida işleme makinelerindeki parçalarda $0,8 \mu \mathrm{m}$ civarında kullanılmıştır [20,21].

Literatürde AISI304 ve AISI316 östenitik paslanmaz çeliklerin EEİ ile işlenmesiyle ilgili birçok çalışma mevcuttur $[3,6,7,9,12,21]$. Bu çalışmalara bakıldığında, EEİ yöntemi; boşalım akımı, vurum süresi, bekleme süresi ve dielektrik tipi gibi birçok parametreye bağlı olduğundan bu parametrelerdeki değişiklikler işparçası işleme hızı, elektrot aşınma hızı, bağıl aşınma ve yüzey pürüzlülüğü gibi çıktı performanslarını doğrudan etkilemektedir. Bu amaçla yapılan çalışmalarda, boşalım akımı, vurum süresi ve bekleme süresi değişken parametreler olarak kullanılarak AISI304 ve AISI316 işparçalarının işleme sonrası yüzey morfolojisi araştırılmıştır [6, 7]. Ayrıca deneysel çalışma sonuçlarıyla işleme parametreleri Taguchi metodu [6, 9, 22] ve Harmony araştırma metoduyla [3] optimize edilmiştir. Yine, AISI316 paslanmaz çeliği işparçası farklı işleme parametreleriyle tel erozyon yöntemiyle işlenerek yüzey pürüzlülüğü ve tekrardan katılaşmış katman özellikleri araştırılmıştır. Deney sonuçlarının MATLAB programında yapay sinir ağ1 modellemesi gerçekleştirilmiştir [12]. AISI304 paslanmaz çeliği farklı işleme parametreleriyle dalma elektro erozyon tezgahında işlenerek girdi-çıktı parametrelerinin Taguchi metoduyla optimizasyonu gerçekleştirilmiştir [9]. 
Bu çalışmada, son yıllarda gıda sanayinde kullanımı büyük artış gösteren AISI304 ve AISI316 östenitik paslanmaz çeliklerin EEİ yöntemiyle işleme performansları deneysel olarak araştırılmıştır. Farklı işleme parametreleriyle (boşalım akımı, vurum süresi ve bekleme süresi) oluşturulan 3 farklı işleme tipi (hassas, orta ve kaba) kullanılarak dalma elektro erozyon tezgahında gerçekleştirilen deneysel çalışma sonucunda işparçası işleme hızı (ï̇̈H), elektrot aşınma hızı $(\mathrm{EAH})$, bağıl aşınma $(\mathrm{BA})$ ve ortalama yüzey pürüzlülüğü $\left(\mathrm{R}_{\mathrm{a}}\right)$ değerleri elde edilmiştir. İşlenmiş yüzeyler optik mikroskop altında incelenmiş ve yorumlanmıştır.

\section{Materyal ve Metot}

Deneysel çalışmalarda, vurum jeneratörlü FURKAN EDM M25 dalma elektro erozyon tezgahı kullanılmıştır. Vurum jeneratörü, $3 \mathrm{kVA}$ güce/kapasiteye ve $80 \mathrm{~V}$ 'luk açık devre gerilimine sahip eş vurumlardan oluşacak şekilde ayarlanmıştır. Deneysel çalışmalarda işparçası olarak 30x30x20mm boyutlarında AISI304 ve AISI316 paslanmaz çelikler kullanılmıştır. Elektrot olarak 10x10x80mm boyutlarında bakır çubuklar kullanılmıştır (Şekil 1a). İşparçaları ve elektrotun özellikleri Tablo 1'de verilmiştir [10, 12, 21]. Dielektrik sıv1 olarak kullanılan Eurolub EDM ER100 ticari EEİ işleme sıvısı işleme bölgesine yanal olarak püskürtülmüştür (Şekil 1a). EDM ER100 dielektrik sıvısı hem çevrecidir hem de gaz yağı dielektrikten çok daha yüksek parlama noktasına $\left(110^{\circ} \mathrm{C}\right)$ sahiptir. Deneysel çalışmalarda işparçası eksi $(-)$, elektrot artı $(+)$ olarak kutuplanmış ve işlemeler gerçekleştirilmiştir (Şekil 1b). Deneylerde kullanılan işleme tipleri Tablo 2'de verilmiştir. Tablo 2'deki işleme tipleri belirlenirken deneylerde kullanılan tezgahın işleme kabiliyetleri göz önünde bulundurulmuştur. EDM 25M tezgahın ayarlanabilecek boşalım akım seviyeleri: 1,5-3-6-12-25A (6 farklı değer) iken vurum süresi seviyeleri 3-6-12-25-

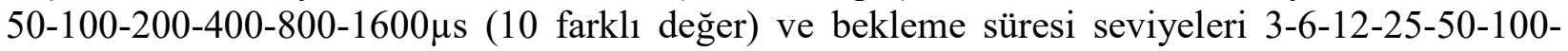
200-400-800-1600 $\mu$ s dir. Tezgahın kabiliyetine göre oluşturulabilecek en hassas işleme tipi için en küçük boşalım akımı $(1,5 \mathrm{~A})$ ve en küçük vurum süresi $(3 \mu \mathrm{s})$ değerleri seçilmiştir (işleme kodu: L). Benzer şekilde, oluşturulabilecek en kaba/hızlı işleme tipi için en büyük boşalım akımı (25A) ve en büyük vurum süresi $(1600 \mu \mathrm{s})$ değerleri seçilmiştir (işleme kodu: H). Orta dereceli bir işleme tipi için 6A boşalım akımı ve $400 \mu$ s vurum süresi değerleri seçilmiştir (işleme kodu: M). Yanıksız ve temiz işlenmiş yüzeyler elde etmek adına her işleme tipi (L, M ve H) için tezgahın çalışma süresi (kafanın dalma süresi) 1,6s ve gerilme çekilme süresi (kafanın kalkma süresi) 1,6s olarak ayarlanmıştır. İşparçası ve elektrotun işleme öncesi ve sonrası ağırlıkları 1/1000 hassasiyette elektronik terazi kullanılarak tartılmıştır. Her deney üç kez tekrarlanıp çıktı değerlerinin aritmetik ortalaması alınarak İIH, EAH ve BA hesaplanmıştır (Eşitlik 1-Eşitlik 3).

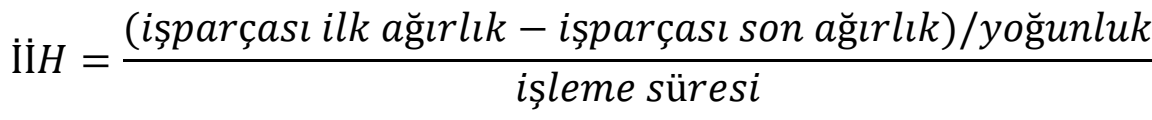

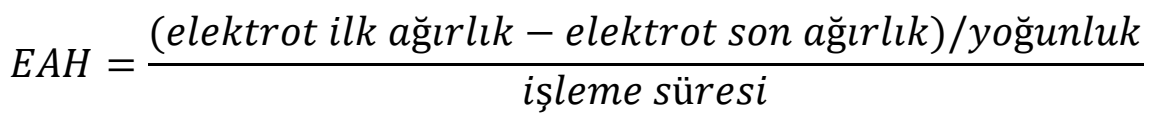

$$
\begin{aligned}
& B A=\frac{E A H}{\dot{\mathrm{I}} \dot{\mathrm{I}} H} x 100
\end{aligned}
$$




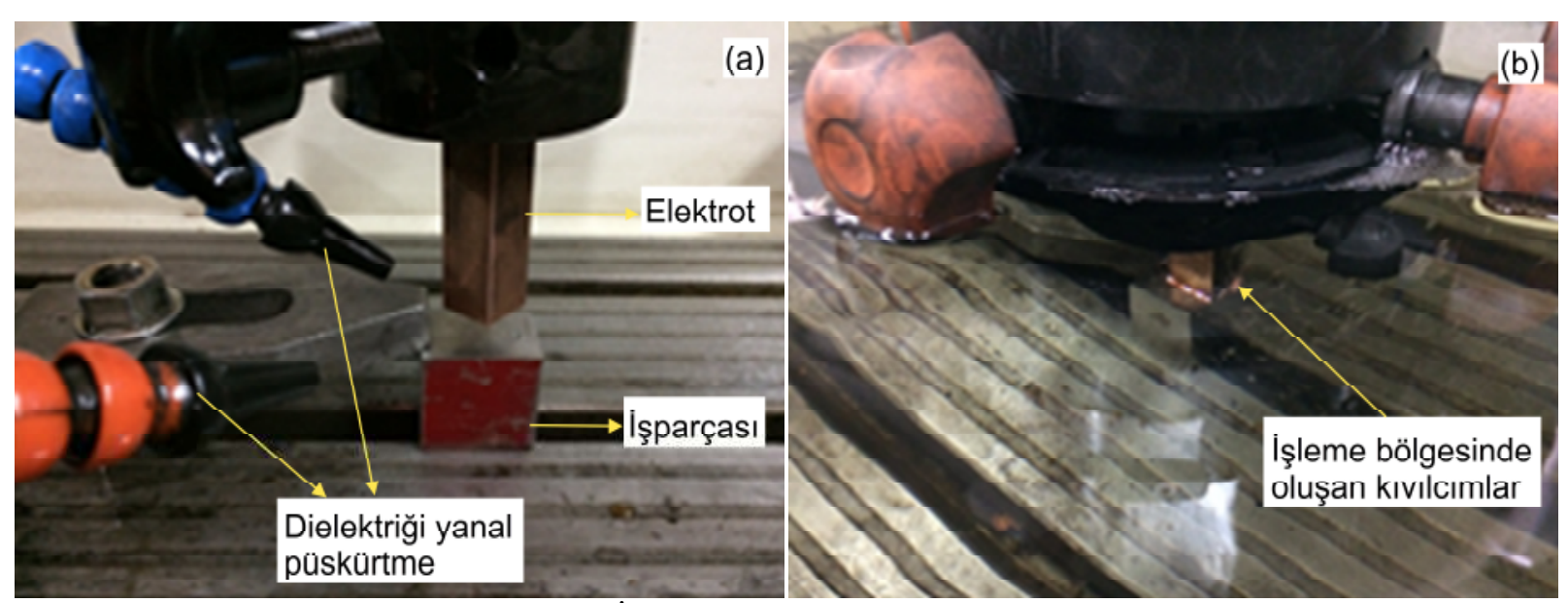

Şekil 1. EEİ: a) işleme pozisyonu, b) işleme anı

Tablo 1. İşparçaları ve elektrotun özellikleri

\begin{tabular}{llll} 
Özellikler - Birim & AISI304 & AISI316 & $\mathrm{Cu}$ \\
\hline Yoğunluk - $\left(\mathrm{kg} / \mathrm{m}^{3}\right)$ & 8000 & 8100 & 8960 \\
Ergime sıcaklığ - (K) & 1728 & 1673 & 1357 \\
Özgül ısı kapasitesi - (J/kg.K) & 500 & 500 & 384 \\
Termal iletkenlik - (W/m.K) & 16,2 & 16,3 & 401 \\
Elektrik iletkenlik - (ohm-cm) & $0,72 \times 10^{-4}$ & $0,74 \times 10^{-4}$ & $1,72 \times 10^{-6}$ \\
\hline
\end{tabular}

Tablo 2. EEİ deneylerinde kullanılan işleme tipleri

\begin{tabular}{llccc}
\hline İşleme & İşleme & \multicolumn{3}{c}{ İşleme parametreleri } \\
tipi & kodu & Boşalım akımı - I (A) & Vurum süresi - $\mathrm{t}_{\text {on }}(\mu \mathrm{s})$ & Bekleme süresi - $\mathrm{t}_{\text {off }}(\mu \mathrm{s})$ \\
\hline Hassas & $\mathrm{L}$ & 1,5 & 3 & 50 \\
Orta & $\mathrm{M}$ & 6 & 400 & 12 \\
Kaba & $\mathrm{H}$ & 25 & 1600 & 3 \\
\hline
\end{tabular}

Yüzey pürüzlülüğü ölçümünde MarSurf PS 10 portatif ölçüm cihazı kullanılmıştır (Şekil 2).

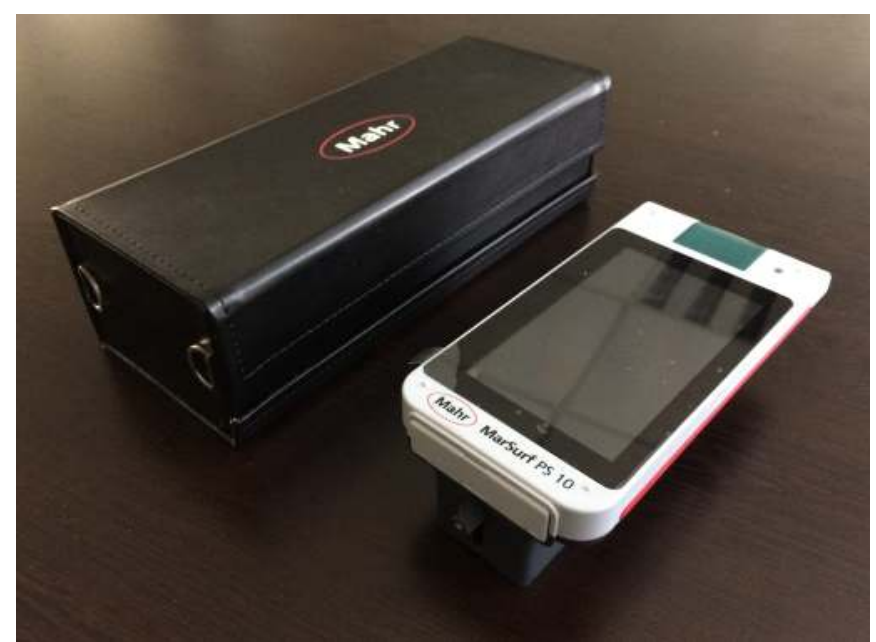

Şekil 2. MarSurf PS 10 tarama uçlu yüzey pürüzlülüğü ölçüm cihazı 
Yüzey pürüzlülüğü ölçümlerinde örnekleme uzunluğu standart tablolardan $0,8 \mathrm{~mm}$ ve ölçüm uzunluğu 2,5mm olarak seçilmiştir. İşparçalarının işlenmiş yüzeyinden üç farklı noktadan alınan ölçümlerin aritmetik ortalaması kullanılmıştır. Mikroyapı incelemesi Olympus marka dijital kamera donanımlı optik mikroskopla gerçekleştirilmiştir. İşlenmiş işparçalarının yüzeyi sodyum hipoklorit $+\% 5$ toz anyonik madde karışımıyla firçalanarak temizlenmiştir. 10 kat büyütmeyle önceden belirlenen noktalardan mikroyapı fotoğrafları çekilmiştir.

\section{Deneysel Sonuçlar ve Tartışmalar}

\subsection{EEI performans çıktıları (İIH, EAH, BA ve $\left.R_{a}\right)$}

AISI304 ve AISI316 östenitik paslanmaz çeliklerin üç farklı işleme tipinde (L, M ve H) gerçekleştirilen EEİ deneylerinin sonuçları Şekil 3-4 verilmiştir. İIHH değerinin, boşalım akımı ve vurum süresi parametreleriyle doğru orantılı olarak değiştiği görülebilmektedir (Şekil 3a). En düşük boşalım akımı ve vurum süresi değerlerine sahip olan L işleme tipinde her iki çelik için de düşük İIH değerleri elde edilirken en yüksek boşalım akımı ve vurum süresine sahip olan $H$ işleme tipinde her iki malzeme için ise yüksek İIH değerleri elde edilmiştir. AISI304 ve AISI316 paslanmaz çelikleri her işleme tipi için İIH değerleri açısından kıyaslandığında, AISI304 çeliği AISI316 çeliğine göre çok büyük farklar görülmese de nispeten daha kolay işlenebilir olduğu tespit edilmiştir. Şekil 3b'den anlaşılacağı üzere EAH değerleri de İIHH değerlerine benzer şekilde, boşalım akımı ve vurum süresi parametreleriyle doğru orantılıdır. L işleme tipinde her iki çelik için de düşük EAH değerleri elde edilirken $\mathrm{H}$ işleme tipinde her iki malzeme için de yüksek EAH değerleri elde edilmiştir. Her işleme tipiyle yapılan deney sonuçları EAH değerleri açısından kıyas yapıldığında, AISI316 çeliği işlenirken elektrotun daha fazla aşındığı tespit edilmiştir.

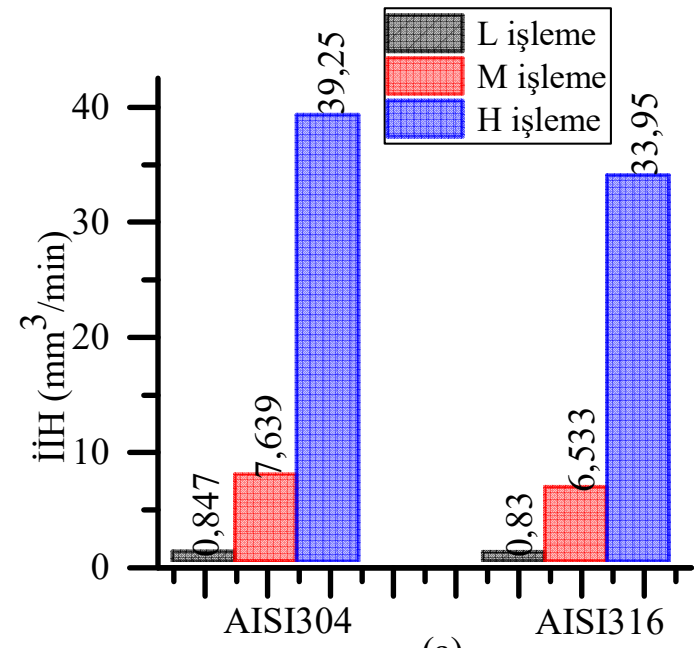

(a)

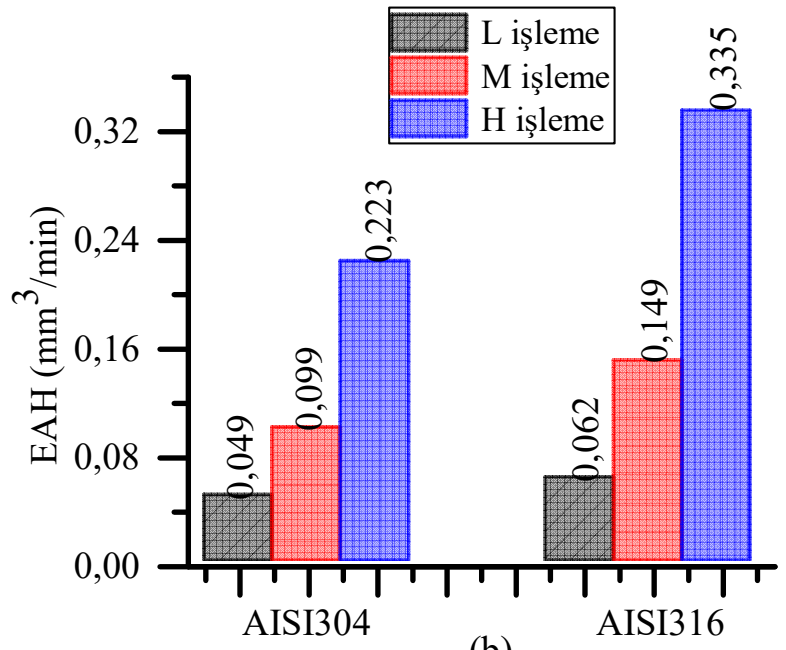

(b)

Şekil 3. AISI304 ve AISI316 çeliklerin üç farklı işleme tipindeki çıktı değerleri: a) İIH, b) EAH

BA değerinin, boşalım akımı ve vurum süresi parametreleriyle ters orantılı olduğu tespit edilmiştir (Şekil 4a). En düşük boşalım akımı ve vurum süresi değerlerine sahip olan L işleme tipinde her iki çelik için de en yüksek BA değerleri elde edilirken en yüksek boşalım akımı ve 
vurum süresine sahip olan $\mathrm{H}$ işleme tipinde her iki malzeme için ise en düşük BA değerleri elde edilmiştir. Bu durum en önemli sebebi; artan boşalım akımı ve vurum süresi değerleri İİH değerini EAH değerine nazaran daha çok artırmaktadır. BA değeri hesabında İIH değeri payda da olduğu için BA değerini azaltmaktadır. Her işleme tipinde AISI316 çeliği daha çok bağll aşınmaya sebebiyet vermektedir. Genel olarak tüm işleme tiplerinde her iki malzeme için EEİ açısından sorun oluşturacak BA değerleri görülmemiştir. $R_{a}$ değerleri boşalım akımı ve vurum süresi parametreleriyle doğru orantılıdır. Artan boşalım akımı ve vurum süresi değerleri $(H$ işleme tipi) çeliklerin $R_{a}$ değerlerini artırırken (yüzeylerin özelliklerini kötüleştirirken) düşük boşalım akımı ve vurum süresi değerleri ( $\mathrm{L}$ işleme tipi) çeliklerin $\mathrm{R}_{\mathrm{a}}$ değerlerini düşürmektedir (Şekil 4b). Her işleme tipinde AISI304 çeliği AISI316 çeliğine nazaran daha iyi yüzey özellikleri sergilemiştir. Hem AISI304 hem de AISI316 paslanmaz çeliklerinin L işleme tipinde elde edilen $\mathrm{R}_{\mathrm{a}}$ değerleri gida işleme makineleri için uygulanan DIN EN 10088-2 standart ve EC98/37/EC yönergesine göre uygun (kabul edilebilir) olduğu tespit edilmiştir [20, 21].

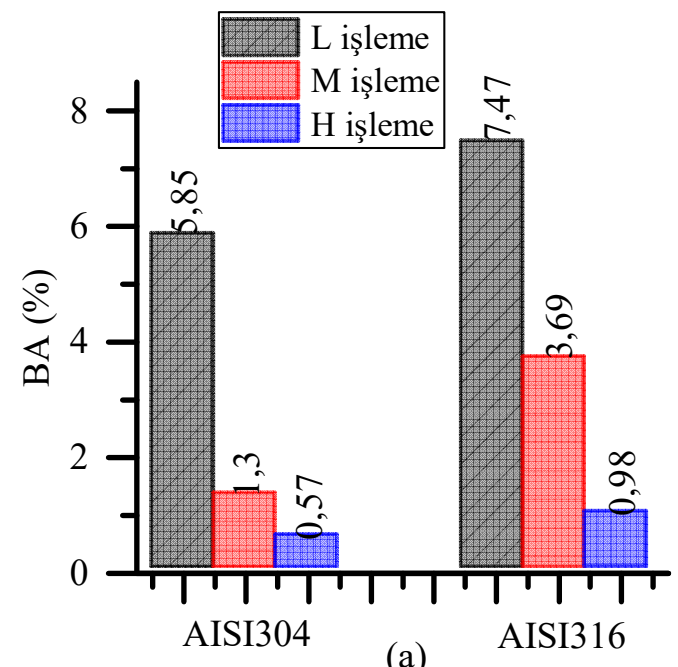

(a)

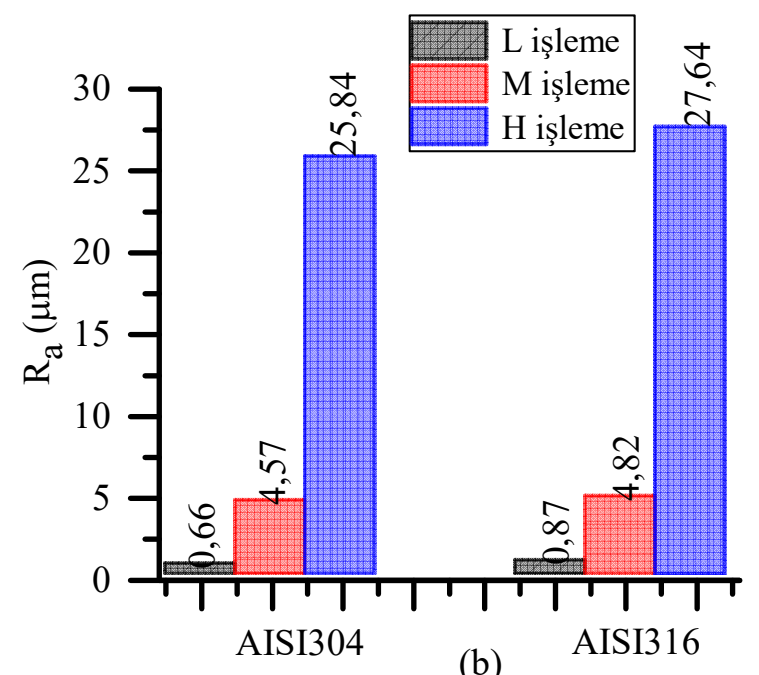

(b)

Şekil 4. AISI304 ve AISI316 çeliklerin üç farklı işleme tipindeki çıktı değerleri: a) BA, b) Ra

\subsection{Mikroyapı incelemesi}

L işleme tipiyle işlenmiş yüzeylerde oluşan kraterlerin oldukça küçük çaplı olduğu görülmüştür (Şekil 5b-6b). Bu durumun en temel sebebi; düşük boşalım akımı değeri (1,5A) ve kısa vurum süresi değeriyle $(3 \mu \mathrm{s})$ yüzeye boşalan kıvılcımların enerjilerinin oldukça küçük olmasıdır. Düşük enerjiye sahip kıvılcımlar yüzeyden küçük hacimlerde ergitme gerçekleştirmektedir. Dolayısıyla yüzeyde daha küçük çaplı ve daha sığ kraterler oluşmaktadır. Böylelikle $R_{a}$ değeri daha küçük elde edilebilmektedir. M ile işlenmiş yüzeylerdeki kraterler ise L ile kıyaslandığında nispeten daha büyük çaplıdır (Şekil 5c-6c). H işleme tipindeki yüzeyde oluşan kraterler hem büyük çaplı hem de oldukça derin oldukları görülmüştür (Şekil 5d-6d). Burada, L işleme tipi için yapılan yorumların tersi geçerlidir. Yüksek boşalım akımı değeri (25A) ve uzun vurum süresi değeriyle $(1600 \mu s)$ oldukça yüksek enerjiye sahip kıvılcımlar elde edilmektedir. Yüksek enerjiye sahip boşalımlar, yüzeyde daha büyük çaplı ve daha derin kraterler oluşturmaktadır. 

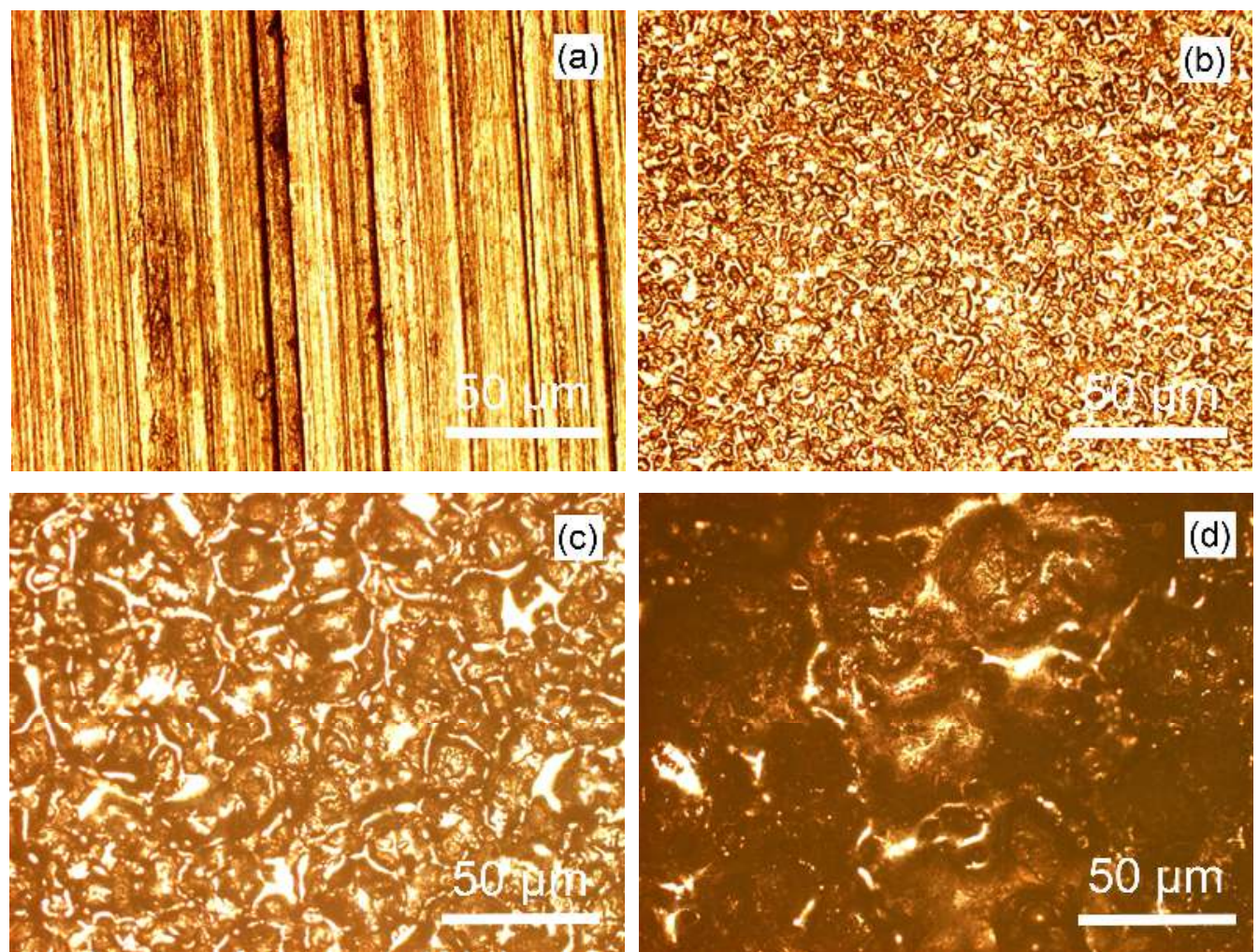

Şekil 5. AISI304 yüzey görüntüleri: a) İşlenmemiş, b) L ile işlenmiş, c) $M$ ile işlenmiş, d) $H$ ile işlenmiş
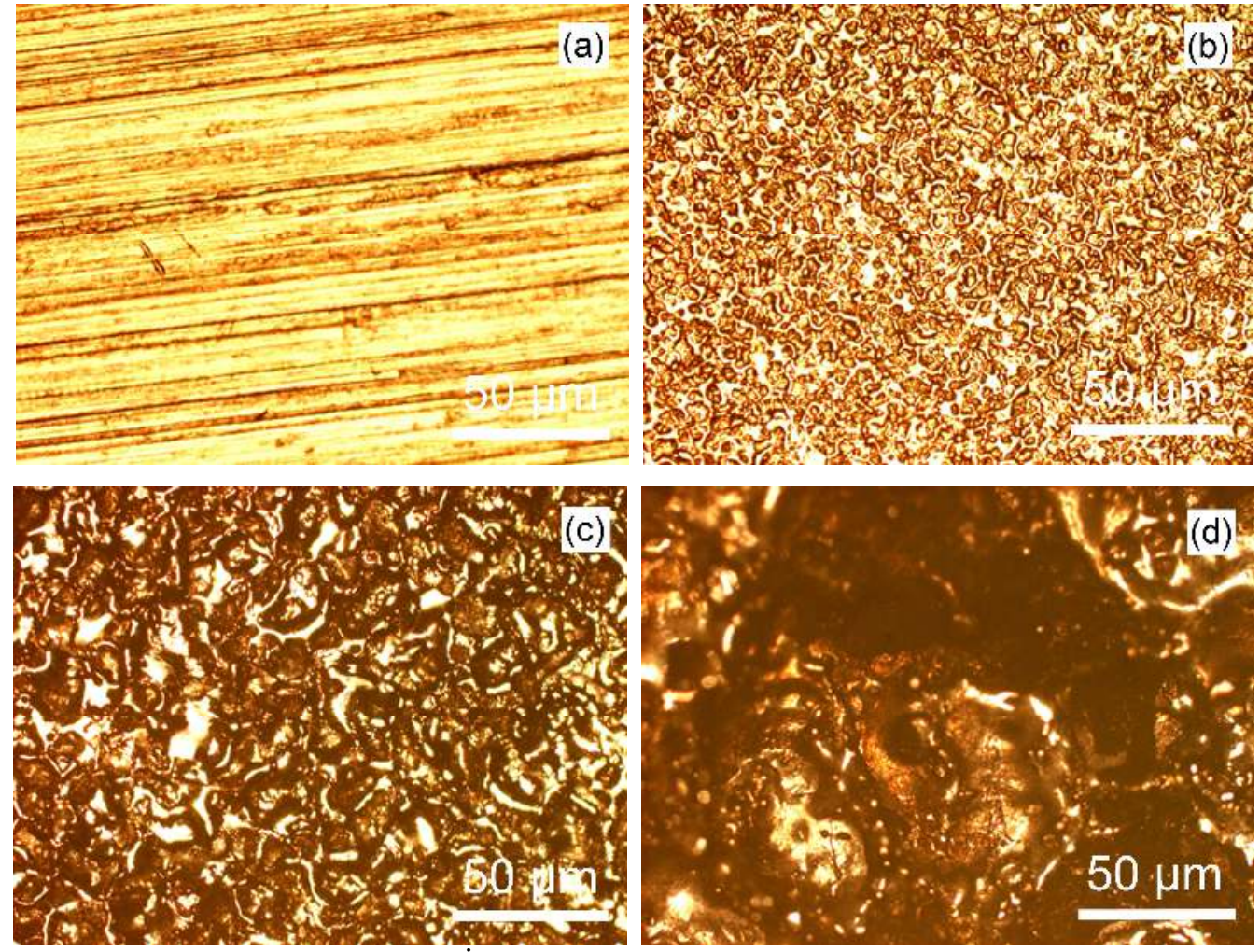

Şekil 6. AISI316 yüzey görüntüleri: a) İşlenmemiş, b) L ile işlenmiş, c) M ile işlenmiş, d) H ile işlenmiş 


\section{Sonuç}

Bu çalışmada, AISI304 ve AISI316 östenitik paslanmaz çeliklerin farklı işleme tipleriyle EEİ performansları araştırılmıştır. Deneysel çalışmalar sonucunda, hassas işleme tipi (L) için oldukça düşük İIH değerleri elde edilirken gida makineleri standartlarına uygun ve kabul edilebilir yüzey pürüzlülüğü (ortalama) değerleri sağlanmıştır. Kaba işleme tipinde $(\mathrm{H})$ talaşlı imalata kıyasla makul İIH değerleri elde edilse de, gıda makineleri standartlarını karşılamayacak (oldukça kötü) yüzeyler tespit edilmiştir. Gıda standartlarınca kabul edilebilir yüzey pürüzlülüğüne sahip makine parçalarını EEİde makul sürelerde (yükssek İIH'de) işleyebilmek için operasyon stratejisi belirlenmesi gerektiği sonucuna varılmıştır. Bunun için işlenecek parçaların geometrik toleransları göz önünde bulundurularak öncelikle kaba işleme, sonra orta işleme ve en sonunda hassas işleme yapılmasıyla arzu edilen beklentileri karşılayabilecek makine parçalarının üretilebileceği düşünülmektedir. Sonuç olarak EEİ yönteminin, gıda işleme makinelerinin östenitik paslanmaz çelik parçalarının imalatında kullanılabilir bir yöntem olabileceği deneysel olarak tespit edilmiştir.

\section{Teşekkür}

$\mathrm{Bu}$ çalışma, Ahi Evran Üniversitesi Bilimsel Araştırma Projeleri Koordinasyon Birimi’nce desteklenmiştir. Proje Numarası: MMF.A4.18.001. Desteklerinden dolayı Bilimsel Araştırma Projeleri Koordinasyon Birimi’ne teşekkürlerimi sunarım.

\section{Kaynaklar}

[1] Yılmaz V, Dilipak H, Özdemir M, Uzun G. Hadfield çeliğine elektro erozyon ile işleme yöntemiyle mikro derin deliklerin delinmesinde yüzey pürüzlülügüünün incelenmesi. International Symposium on Innovative Technologies in Engineering and Science (ISITES2014), Karabük, Turkey, 2014; 156-164.

[2] Shankar S, Maheshwari S, Pandey .P.C. Some investigations into the electric discharge machining of hardened tool steel using different electrode materials. Journal of Materials Processing Technology 2004; 149: 272-277.

[3] Deris AM, Zain AM, Sallehuddin R, Sharif S. Harmony search optimization in dimensional accuracy of die sinking EDM process using SS316L stainless steel. Journal of Physics: Conference Series 2017; 892: 1-10.

[4] Puhan D, Mahapatra SS, Sahu J, Das L. A hybrid approach for multi-response optimization of non-conventional machining on AlSiCp MMC. Measurement 2013; 46: 3581-3592.

[5] Erdem O, Çoğun C, Uslan İ. Investigation of electrical discharge drilling (EDD) performance of Ti-6Al-4V super alloy. 1st International Symposium on Light Alloys and Composite Materials (ISLAC'18), Karabük, Turkey, 2018; 124-125.

[6] Lundberg M, Saarimaki J, Moverare JJ, Calmunger M. Surface integrity and fatigue behaviour of electric discharged machined and milled austenitic stainless steel. Materials Characterization 2017; 124: 215-222.

[7] Kumar UA, Laxminarayana P, Aravindan N. Study of surface morphology on micro machined surfaces of AISI316 by Die Sinker EDM. Materials Today: Proceedings 2017; 4: 
1285-1292.

[8] Zeyveli M, Altuğ M, Güldaş A. Dubleks paslanmaz çeliğin tel erozyon ile işlenebilirliğinin deneysel araştırılması. International Symposium on Innovative Technologies in Engineering and Science (ISITES2014), Karabük, Turkey, 2014; 303-308.

[9] Buschaiah K, Rao MJ, Krishnaiah A. Investigation on the influence of Edm parameters on machining characteristics for Aisi 304. Materials Today: Proceedings 2018; 5: 3648-3656.

[10] Erdem O, Çoğun C, Urtekin L, Özerkan HB, Uslan İ. Toz katkılı ve 1sıtılmış dielektriğin elektro erozyon ile işlemede (EEI) delik delme performansı üzerine etkisi. Journal of the Faculty of Engineering and Architecture of Gazi University 2016; 31: 531-544.

[11] Assarzadeh S, Ghoreishi M. Prediction of root mean square surface roughness in low discharge energy die-sinking EDM process considering the effects of successive discharges and plasma flushing efficiency. Journal of Manufacturing Processes 2017; 30: 502-515.

[12] Choudhuri B, Sen R, Ghosh SK, Saha SC. Study of surface integrity and recast surface machined by wire electrical discharge machining. Materials Today: Proceedings 2018; 5: 7515-7524.

[13] Meshram DB, Puri YM, Review of research work in die sinking EDM for machining curved hole. J Braz. Soc. Mech. Sci. Eng. 2017; 39: 2593-2605.

[14] Ishfag K, Mufti NA, Mughal MP, Saleem MQ, Ahmed N. Investigation of wire electric discharge machining of stainless-clad steel for optimization of cutting speed. International Journal of Advanced Manufacturing Technology 2018; 96: 1429-1443.

[15] Bozdana AT, Al-Karkhi NK. Comparative experimental investigation and gap flow simulation in electrical discharge drilling using new electrode geometry. Mechanical Sciences 2017; 8: 289-298.

[16] Singh AK, Kumar S, Singh VP. Effect of the addition of conductive powder in dielectric on the surface properties of superalloy Super Co 605 by EDM process. International Journal Advanced Manufacturing Technol 2015; 77: 99-106.

[17] Hourmand M, Farahany S, Sarhan AAD, Noordin MY. Investigating the electrical discharge machining (EDM) parameter effects on Al-Mg2Si metal matrix composite (MMC) for high material removal rate (MRR) and less EWR-RSM approach. International Journal Advanced Manufacturing Technol 2015; 77: 831- 838.

[18] Unses E, Cogun C. Improvement of electric discharge machining (EDM) performance of Ti-6Al-4V alloy with added graphite powder to dielectric, Strojniski Vestnik-Journal of Mechanical Engineering 2015; 61: 409-418.

[19] Saklakoğlu N, İrizalp Gençalp S, Gökdemir ZE, Polat S. AISI 304 ve 316 paslanmaz çeliğinin $\mathrm{HCl}$ ve $\mathrm{H} 2 \mathrm{SO} 4$ çözeltilerindeki gerilim korozyon çatlaması davranışı. Dicle Üniversitesi Mühendislik Fakültesi Mühendislik Dergisi 2016; 7: 139-150.

[20] Doruk İ. Gıda sanayinde kullanılan paslanmaz çelikler ve bu çeliklere uygulanan kaynak yöntemleri. Yüksek Lisans Tezi, Pamukkale Üniversitesi Fen Bilimleri Enstitüsü, Denizli (2005).

[21] Partington ER. New guidence documents governing the selection and safety evaluation of materials for food use. 4th European Stainless Steel Sciebce and Market Congress, Paris, France, 2002, 28-37.

[22] Ugrasen G, Singh MRB, Ravindra HV. Optimization of process parameters for SS304 in wire electrical discharge machining using Taguchi's Technique. Proceedings 2018; 5: 28772883. 